\title{
Dipeptidyl Peptidase-4 Inhibitors in Type 2 Diabetes Therapy
}

\author{
a report by \\ Baptist Gallwitz
}

Professor of Medicine, Department of Medicine IV, Eberhard-Karls University of Tübingen DOI:10.17925/EE.2008.04.00.40

The prevalence of type 2 diabetes is rising dramatically, and some predictions state that the worldwide number of subjects with diabetes by 2030 will be 370 million, along with a concomitant rise in prediabetic conditions. ${ }^{1}$ Since type 2 diabetes is increasing and most patients do not reach their therapeutic goals, novel treatment options are needed.

While insulin resistance is constant in the course of type 2 diabetes, islet function declines continuously over time, and disease progression of type 2 diabetes is characterised by a loss of islet function. Hyperglycaemia, free fatty acids, cytokines, adipokines and toxic metabolic products may lead to a loss of $\beta$-cell function and $\beta$-cell mass in the islets. The $\alpha$ cells in the islet additionally develop a disturbance of glucagon secretion. In healthy subjects, glucagon secretion is suppressed under hyperglycaemic conditions, whereas in type 2 diabetes glucagon secretion is elevated, leading to excessive glucose production by the liver. ${ }^{2}$

The therapeutic options currently available do not address the problem of islet-cell dysfunction. Both sulfonylureas and glinides stimulate insulin secretion from the $\beta$ cells, metformin and glitazones act on insulin resistance and $\alpha$-glucosidase inhibitors delay the digestion of sucrose and the breakdown of complex carbohydrates. Exogenous insulin replaces the endogenous secretory insulin deficit, although it potentially causes weight gain and hypoglycaemia. The progressive loss of islet function observed in type 2 diabetes is not ameliorated by any of the current therapeutic options. ${ }^{3}$

\section{Incretin Hormones and Incretin-based Therapies}

The incretin hormones glucose-dependent insulinotropic peptide (GIP) and glucagon-like peptide-1 (GLP-1) stimulate insulin secretion after a meal. ${ }^{4}$ The incretin effect - which leads to an enhanced insulin response

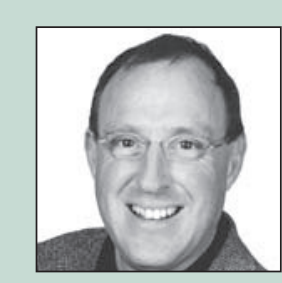

Baptist Gallwitz is a Professor of Medicine in the Department of Medicine IV at Eberhard-Karls University of Tübingen, where his clinical position is Head of the Outpatient Department for Endocrinology and Diabetes. His main scientific focus is on the physiology of incretin hormones. He was Senior Registrar from 1999 and was an Associate Professor at the St Josef-Hospital Medical School Ruhr-University Bochum until 2003, when he took up his post in Tübingen. He is a member of the American Diabetes Association (ADA), the European Association for the Study of Diabetes (EASD) and the German Diabetes Association (DDG), and various other scientific and medical associations. He is also a member of the Editorial Boards of various international diabetes journals. Dr Gallwitz specialised in internal medicine, endocrinology and gastroenterology at the Universities of Göttingen and Kiel. After university and medical school in Essen, Berlin, London and Munich, he finished his PhD on insulin signal transduction at the Diabetes Research Institute, University of Munich in 1986

E: baptist.gallwitz@med.uni-tuebingen.de after oral glucose compared with intravenous glucose - is reduced or even absent in patients with type 2 diabetes, ${ }^{5}$ but can be restored by raising concentrations of the incretin hormones.

The promising therapeutic potential of GLP-1 as a pharmacological tool for treating type 2 diabetes was discovered in the 1990s. In contrast to other insulinotropic agents, e.g. the sulfonylureas, the insulinotropic effect of GLP-1 depends even more closely on the actual glucose concentration, which allows the possibility of glucose normalisation without the risk of hypoglycaemia. In patients with type 2 diabetes, exogenous GLP-1 increases insulin secretion and normalises both fasting and post-prandial blood glucose. Furthermore, it has the ability to restore the blunted first phase of insulin secretion in type 2 diabetes. ${ }^{6}$

Besides the glucose-lowering effects, GLP-1 has a variety of additional 'non-insulinotropic' physiological actions that may be advantageous in type 2 diabetes therapy, i.e. it suppresses glucagon secretion from the $\alpha$ cells and slows gastric emptying. Therefore, it contributes to satiety and to a slower passage and resorption of carbohydrates. Additionally, GLP-1 acts as a mediator of satiety in the hypothalamus, where it is also found as a neurotransmitter. ${ }^{3}$ Patients with type 2 diabetes having received GLP-1 as a continuous infusion have lost bodyweight. ${ }^{7}$ Furthermore, GLP-1 stimulates $\beta$-cell formation from precursor cells and also inhibits their apoptosis, leading to an increase in $\beta$-cell mass and to an improvement in $\beta$-cell function. ${ }^{8}$

\section{Dipeptidyl Peptidase-4 Inhibitors Utilise \\ Incretin Action in Type 2 Diabetes}

Due to the action of dipeptidyl peptidase-4 (DPP-4), the biological halflife of exogenous GLP-1 is only one to two minutes, therefore treatment with native GLP-1 is not feasible. DPP-4 is a ubiquitous enzyme that can be detected in the endothelium of different organs and is measurable as circulating enzymatic activity in plasma. Besides GLP-1 and GIP, additional peptides, such as pituitary adenylate cyclase-activating polypeptide (PACAP) and gastrin-releasing peptide (GRP), are substrates of DPP-4 (see Table 1). However, DPP-4 has a greater affinity to GLP-1 than other peptides, including GIP. DPP-4 cleaves and inactivates GLP-1 within a few minutes. ${ }^{9}$ DPP-4 preferentially cleaves peptides with the amino acid alanine or proline in position 2 of the $\mathrm{N}$-terminus of the peptide chain. The degradation products of GLP-1 are a dipeptide (His-Ala) and GLP-1(9-36)amide, which has GLP-1-antagonistic properties under various conditions. ${ }^{9}$ In order to utilise the GLP-1 effects, long-acting GLP-1 receptor agonists have been developed as an injectable therapy and DPP-4 inhibitors as oral treatment option. ${ }^{6}$

DPP-4 is also expressed as CD26 on the cell membrane of activated $T$ lymphocytes. Here, the enzymatic properties of the DPP-4/CD-26 
molecule do not seem to be important. Therefore, the influence of DPP-4 inhibitors on immunological CD26-mediated functions is not expected. In clinical studies with DPP-4 inhibitors, no serious side effects or adverse effects on immunological regulatory mechanisms were observed. 6

DPP-4 belongs to a whole enzyme family of endopeptidases; therefore, DPP-4 inhibitors need to be highly selective in order to inhibit DPP-4 only and not other DPPs. The DPP-4 inhibitors sitagliptin (Merck Pharmaceuticals) and vildagliptin (Novartis Pharmaceuticals) are two compounds of the DPP-4 inhibitor class that have been approved in various countries. Currently undergoing clinical studies are alogliptin (Takeda Pharmaceuticals), ${ }^{10}$ BI-1356 (Boehringer Ingelheim Pharmaceuticals) ${ }^{11}$ and saxagliptin (AstraZeneca and Brystol-Myer-Squibb Pharmaceuticals). ${ }^{12}$ The structures of the molecules are shown in Figure 1, and more DPP-4 inhibitors are in development.

Sitagliptin and vildagliptin are more highly selective compared with other proline-selective peptidases. In humans, the pharmacokinetic and pharmacodynamic properties and tolerability have been assessed in numerous clinical studies. Post-prandially active endogenous GLP-1 concentrations are increased two- to three-fold by DPP-4 inhibitors. They also have a low propensity to be involved in drug-drug interactions as either a perpetrator or a substrate for metabolism, especially with other antihyperglycaemic oral agents. ${ }^{13,14}$ In clinical studies and broad clinical application to date they have been safe, with an intrinsic hypoglycaemia risk near the level of metformin or placebo. Hypoglycaemia occurs only when combined with sulfonylureas. Nasopharyngitis, urinary tract infections, gastrointestinal symptoms and skin reactions are adverse events that are reported infrequently. ${ }^{15,16}$

It is debatable whether DPP-4 inhibitors are able to positively influence the disease progression of type 2 diabetes by slowing the loss of $\beta$-cell mass and function. The effect of sitagliptin and vildagliptin was investigated extensively in animal models. DPP-4 inhibitors increased the number of insulin-positive $\beta$ cells in islets and the $\beta$ - to $\alpha$-cell ratio in different diabetic animals was normalised. Additionally, the islet insulin content was higher and glucose-stimulated insulin secretion in isolated islets was improved compared with glipizide-treated mice.

According to the results from animal

studies, DPP-4 inhibitors may have the potential to delay or prevent disease progression in type 2 diabetes and to improve $\beta$-cell mass and function.

According to the results from animal studies, DPP-4 inhibitors may have the potential to delay or prevent disease progression in type 2 diabetes and to improve $\beta$-cell mass and function. ${ }^{13,14}$ In accordance with this, in DPP-4-deficient mice (CD26-/-; DPP-4 knockout mice) the concentrations of circulating, intact GLP-1 and GIP are elevated and these animals are resistant to streptozotocin-induced $\beta$-cell destruction. ${ }^{17}$ In man, the long-term effects of DPP-4 inhibitor
Table 1: Important Substrates of Dipeptidyl Peptidase $-4^{9}$

\begin{tabular}{ll}
$\begin{array}{l}\text { With Influence on Activity } \\
\text { and Elimination }\end{array}$ & $\begin{array}{l}\text { Without Influence on } \\
\text { Activity or Elimination }\end{array}$ \\
\hline GLP-1 & GRH \\
\hline GIP & Interleukin-1 $\beta$ \\
\hline GLP-2 & Interleukin-2 \\
\hline PACAP & IGF-1 \\
\hline Neuropeptide Y & Prolactin \\
\hline Peptide YY & hCG \\
\hline Substance P & Bradykinin \\
\hline RANTES & \\
\hline GRH & \\
\hline
\end{tabular}

GLP = glucagon-like peptide; $G R H$ = growth-hormone-releasing hormone; GIP = glucosedependent insulinotropic peptide; PACAP = pituitary adenylate cyclase-activating polypeptide; IGF = insulin-like growth factor; $h C G=$ human chorionic gonadotropin; RANTES = regulated on activation normal $T$ cell expressed and secreted.

Figure 1: Chemical Structure of Dipeptidyl Peptidase-4 Inhibitors

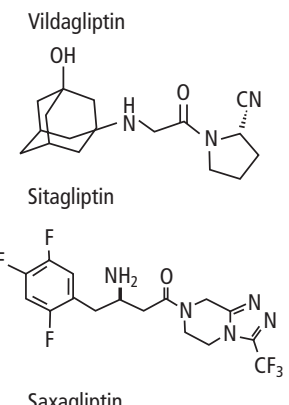<smiles>CN(Cc1ccccc1C#N)C(=O)N(C)C(=O)/C=C/N1CCC[C@@H](N)C1</smiles>
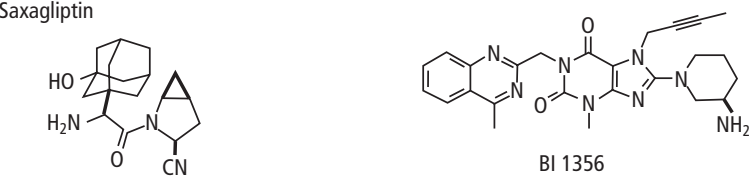

treatment on $\beta$-cell function need to be assessed in clinical studies lasting up to two years, and surrogate parameters for $\beta$-cell function improved. ${ }^{18,19}$ Detailed studies on the mechanisms of $\beta$ - and $\alpha$-cell mass regulation and the regulation of insulin production and insulin secretion in this regard will be necessary to clarify the role of DPP-4 inhibitors in influencing the course of type 2 diabetes.

\section{Clinical Studies with Dipeptidyl Peptidase-4 Inhibitors}

All clinical studies with either sitagliptin or vildagliptin in monotherapy or in combination with other antidiabetic treatment options are summarised in Table 2. In monotherapy, sitagliptin and vildagliptin improved glycaemic control in both the fasting and post-prandial states, as well as $\beta$-cell function in patients with type 2 diabetes. Both led to a significant reduction in glycated haemoglobin $\left(\mathrm{HbA}_{1 \mathrm{c}}\right)$ compared with placebo and with fasting plasma glucose reductions in clinical studies of up to 104 weeks. ${ }^{15,16,18-21}$ In meal tolerance tests, two-hour post-prandial plasma glucose concentrations were also significantly reduced. Parameters for $\beta$-cell function (post-prandial insulin and C-peptide responses, homeostasis model assessment [HOMA]-B and proinsulin-insulin ratio) were improved. Treatment with DPP-4 inhibitors was weight-neutral. In head-to-head comparisons of DPP-4 monotherapy with either metformin or rosiglitazone monotherapy in drug-naïve patients, the efficacy in improving glycaemic parameters was comparable. ${ }^{13-15}$ In a 12-week dosefinding study with saxagliptin in monotherapy in drug-naïve patients, the saxagliptin dose improved the glycaemic parameters of $\mathrm{HbA}_{1 \mathrm{c}}$ and fasting and post-prandial glucose. ${ }^{12}$ 
Table 2: Clinical Studies with Sitagliptin and Vildagliptin with a Duration of 18 Weeks and Longer

\begin{tabular}{|c|c|c|c|c|c|c|c|c|}
\hline References & Compound & $\begin{array}{r}\text { Dose per Day } \\
(\mathrm{mg})\end{array}$ & $\begin{array}{l}\text { Patient } \\
\text { Number }\end{array}$ & $\begin{array}{l}\text { Duration } \\
\text { (weeks) }\end{array}$ & $\begin{array}{l}\text { Other } \\
\text { Treatment }\end{array}$ & $\begin{array}{l}\text { Change in } \\
\text { Glycated } \\
\text { Haemoglobin }(\%)^{*}\end{array}$ & $\begin{array}{l}\text { Effect on } \\
\text { Fasting Plasma } \\
\text { Glucose (nmol/l)* }\end{array}$ & Weight $(\mathrm{kg})^{*}$ \\
\hline \multirow[t]{2}{*}{ Aschner et al..21 } & Sitagliptin & $100 \mathrm{qd}$ & 741 & 24 & Diet & -0.79 & -1 & +0.9 \\
\hline & & $200 \mathrm{qd}$ & & & & -0.94 & -1.2 & \\
\hline Charbonel et al. ${ }^{23}$ & Sitagliptin & $100 \mathrm{qd}$ & 701 & 24 & Metformin & -0.65 & -1.4 & +0.1 \\
\hline Rosenstock et al. ${ }^{28}$ & Sitagliptin & $100 \mathrm{qd}$ & 353 & 24 & Pioglitazone & -0.70 & -0.9 & +0.3 \\
\hline \multirow[t]{2}{*}{ Raz et al.29 } & Sitagliptin & $100 \mathrm{qd}$ & 521 & 18 & Diet & -0.60 & -1.1 & +0.5 \\
\hline & & $200 \mathrm{qd}$ & & & & -0.48 & -1 & +0.1 \\
\hline \multirow[t]{2}{*}{ Nauck et al. ${ }^{22}$} & Siatgliptin & $100 \mathrm{qd}$ & 1,172 & 52 & Metformin & -0.67 & -0.56 & -1.5 \\
\hline & Glipizide & $5-20 \mathrm{qd}$ & & 52 & Metformin & -0.67 & -0.42 & +1.1 \\
\hline \multirow[t]{5}{*}{ Goldstein et al. ${ }^{25}$} & Sitagliptin & $100 \mathrm{qd}$ & 1,091 & 24 & Diet & -0.83 & -1.25 & \\
\hline & Metformin & 500 bid & & & Diet & -0.99 & -1.76 & \\
\hline & Metformin & 1,000 bid & & & Diet & -1.30 & -1.87 & \\
\hline & Sitagliptin & $50 \mathrm{bid}$ & & & Metformin 1,000 & -1.57 & -2.82 & \\
\hline & Sitagliptin & $50 \mathrm{bid}$ & & & Metformin 2,000 & -2.07 & -3.71 & \\
\hline \multirow[t]{2}{*}{ Hermansen et al..$^{26}$} & Sitagliptin & $100 \mathrm{qd}$ & 441 & 24 & Glimepiride & -0.57 & -1.01 & +1.1 \\
\hline & Sitagliptin & $100 \mathrm{qd}$ & & & $\begin{array}{l}\text { Glimepiride/ } \\
\text { metformin }\end{array}$ & -0.89 & -1.10 & +1.3 \\
\hline \multirow[t]{2}{*}{ Scott et al. ${ }^{30}$} & Sitagliptin & $100 \mathrm{qd}$ & 273 & & Metformin & -0.5 & -0.3 & +.04 \\
\hline & Rosiglitazone & $8 \mathrm{qd}$ & & & Metformin & -0.6 & -1 & +2.3 \\
\hline Ahren et al. ${ }^{31}$ & Vildagliptin & $50 \mathrm{qd}$ & 71 & 52 & Metformin & -1.2 & & \\
\hline \multirow[t]{6}{*}{ Rosentock et al. ${ }^{32}$} & Pioglitazone & $30 \mathrm{qd}$ & 607 & 24 & Diet & -1.4 & -1.9 & +1.5 \\
\hline & Vildagliptin/ & $50 / 15 \mathrm{qd}$ & & & & -1.7 & -2.4 & +1.4 \\
\hline & Pioglitazone & & & & & & & \\
\hline & Vilda/ & $100 / 30 \mathrm{qd}$ & & & & -1.9 & -2.8 & +2.1 \\
\hline & Pioglitazone & & & & & & & \\
\hline & Vildagliptin & $100 \mathrm{qd}$ & & & & -1.1 & -1.3 & +0.2 \\
\hline \multirow[t]{2}{*}{ Garber et al. ${ }^{33}$} & Vildagliptin & $50 \mathrm{qd}$ & 463 & 24 & Pioglitazone & -0.5 & -0.3 & -1.3 \\
\hline & Vildagliptin & $50 \mathrm{bid}$ & & & & -0.7 & -0.5 & -0.1 \\
\hline \multirow[t]{2}{*}{ Garber et al. ${ }^{34}$} & Vildagliptin & $50 \mathrm{qd}$ & 515 & 24 & Glimepiride & -0.65 & -0.5 & -0.3 \\
\hline & Vildagliptin & $50 \mathrm{bid}$ & & & & -0.70 & -0.6 & +1.7 \\
\hline \multirow[t]{3}{*}{ Pi-Sunyer et al. ${ }^{35}$} & Vildagliptin & $50 \mathrm{qd}$ & 354 & 24 & Diet & -0.5 & -0.6 & -1 \\
\hline & Vildagliptin & 50 bid & & & & -0.7 & -1.3 & +1.4 \\
\hline & Vildagliptin & $100 \mathrm{qd}$ & & & & -0.8 & -1.2 & -1 \\
\hline Fonseca et al. ${ }^{36}$ & Vildagliptin & 50 bid & 296 & 24 & Insulin\# & -0.3 & -0.6 & +1 \\
\hline \multirow[t]{2}{*}{ Bosi et al. ${ }^{37}$} & Vildagliptin & $50 \mathrm{qd}$ & 544 & 24 & Metformin & -0.7 & -1.5 & +0.6 \\
\hline & Vildagliptin & $50 \mathrm{bid}$ & & & & -1.1 & -2.4 & +1.2 \\
\hline \multirow[t]{2}{*}{ Rosenstock et al..$^{38}$} & Vildagliptin & $50 \mathrm{bid}$ & 786 & 24 & Diet & -1.1 & -1.3 & -0.3 \\
\hline & Rosiglitazone & $8 \mathrm{qd}$ & & & & -1.3 & -2.3 & +1.6 \\
\hline \multirow[t]{2}{*}{ Schweizer et al. ${ }^{39}$} & Vildagliptin & $50 \mathrm{bid}$ & 780 & 52 & Diet & -1 & -0.9 & +0.3 \\
\hline & Metformin & $1,000 \mathrm{bid}$ & & & & -1.4 & -1.7 & -1.9 \\
\hline \multirow[t]{2}{*}{ Bolli et al..$^{40}$} & Vildagliptin & $50 \mathrm{bid}$ & 576 & 24 & Metformin & -0.9 & -1.4 & +0.2 \\
\hline & Pioglitazone & $30 \mathrm{qd}$ & & & & -1 & -2.1 & +2.1 \\
\hline Scherbaum et al. ${ }^{20}$ & Vildagliptin & $50 \mathrm{qd}$ & 306 & 52 & Diet & -0.4 & -0.3 & -0.3 \\
\hline \multirow[t]{3}{*}{ Dejager et al. ${ }^{41}$} & Vildagliptin & $50 \mathrm{qd}$ & 632 & 24 & Diet & -0.5 & -0.9 & -0.4 \\
\hline & Vildagliptin & $50 \mathrm{bid}$ & & & & -0.5 & -0.7 & +1.1 \\
\hline & Vildagliptin & $100 \mathrm{qd}$ & & & & -0.6 & -0.7 & +0.6 \\
\hline
\end{tabular}

${ }^{*}=$ values are placebo-corrected; bid = twice daily; $q d=$ daily. \# = insulin dose increased 1.2U/d in vildagliptin group compared with $4.1 \mathrm{U} / \mathrm{d}$ in placebo group. Baseline mean insulin dose $83 \mathrm{U} / \mathrm{d}$ in both groups.

As an add-on combination to ongoing metformin therapy in patients with type 2 diabetes not reaching therapeutic goals, both DPP-4 inhibitors reduced $\mathrm{HbA}_{1 \mathrm{c}}$ and fasting and post-prandial plasma glucose. The reduction in $\mathrm{HbA}_{1 \mathrm{c}}$ after adding sitagliptin was identical to the reduction after adding the sulfonylurea glipizide to ongoing therapy with metformin. ${ }^{22,23}$ The $\beta$-cell function parameters mentioned above were also improved. The combination of sitagliptin and metformin led to significantly higher GLP-1 concentrations than either therapy alone; however, the mechanism behind this phenomenon is not completely understood. The additional DPP-4 inhibitor therapy was generally well tolerated, and no increased incidence of hypoglycaemia or adverse events were observed. ${ }^{15,24-26}$
In combination studies, DPP-4 inhibitors as an add-on therapy to pioglitazone monotherapy were investigated in patients. Similarly, as observed in the above-mentioned studies, the glycaemic parameters were reduced and more patients reached a target $\mathrm{HbA}_{1 c}<7 \%$ with the combination therapy. $\beta$-cell function parameters also improved with the add-on therapy. Sitagliptin and vlidagliptin were well tolerated in relation to adverse events, including hypoglycaemia. The additional DPP-4 inhibitor therapy was weight-neutral. ${ }^{13-15}$

A direct comparison of sitagliptin added to an ongoing treatment with metformin showed similar efficacy to the addition of glipizide 
to metformin. Sitagliptin was non-inferior in this 52 -week study compared with glipizide. $\mathrm{HbA}_{1 \mathrm{c}}$ and fasting glucose decreased equally in both groups. As expected, the occurrence of hypoglycaemic episodes was much greater in the glipizide group than in the sitagliptin group. Bodyweight showed an increase of $1.1 \mathrm{~kg}$ in the glipizidetreated patients, whereas the patients on sitagliptin experienced weight loss of $1.5 \mathrm{~kg} .{ }^{22}$

\section{Conclusions}

The therapeutic principle of GLP-1 with multiple modes of action, in addition to its glucose-normalising effect, adds a completely novel and attractive perspective to diabetes therapy. The inhibition of glucagon secretion and the improvement of $\beta$-cell function address unmet and important needs in type 2 diabetes therapy.

DPP-4 inhibitors are oral agents that do not exclusively act via pharmacological concentrations of GLP-1-like activity, but raise endogenous levels of GIP and other peptide hormones possibly involved in metabolic control within the physiological range. ${ }^{27}$ The DPP-4 inhibitors sitagliptin and vildagliptin have been shown to be effective, well tolerated and safe over a two-year time period in clinical studies. Long-term safety based on CD26 effects remain unknown, but to date no significant alterations of immune function have been observed. Both of the DPP-4 inhibitors have been effective in monoand combination therapies with metformin or thiazolidinediones. They did not show an increased incidence of hypoglycaemic events in mono- or combination therapies, and the incidence of adverse events was comparable to the incidence observed in the control groups.

Whether therapy with DPP-4 inhibitors is capable of influencing the natural progressive course of type 2 diabetes with $\beta$-cell failure is not yet known. If the effects of DPP-4 inhibitors observed on $\beta$-cell mass and function in pre-clinical studies are also applied to human studies, DPP-4 inhibitors could eventually be used in pre-diabetic stages and the early stages of diabetes to slow or prevent the progression of type 2 diabetes.
1. Smyth $S$, Heron $A$, Diabetes and obesity: the twin epidemics, Nat Med, 2006;12:75-80.

2. Prentki $\mathrm{M}$, Nolan $\mathrm{CJ}$, Islet beta cell failure in type 2 diabetes, J Clin Invest, 2006;116:1802-12.

3. Gallwitz B, Therapies for the treatment of type 2 diabetes mellitus based on incretin action, Minerva Endocrinol, 2006; 31:133-47.

4. Creutzfeldt W, The incretin concept today, Diabetologia, 1979; 16:75-85.

5. Nauck MA, Heimesaat MM, Orskov C, et al., Preserved incretin activity of glucagon-like peptide 1 [7-36 amide] but not of synthetic human gastric inhibitory polypeptide in patients with type-2 diabetes mellitus, I Clin Invest, 1993;91:301-7.

6. Drucker DJ, Nauck MA, The incretin system: glucagon-like peptide-1 receptor agonists and dipeptidyl peptidase-4 inhibitors in type 2 diabetes, Lancet, 2006;368:1696-1705.

7. Zander M, Madsbad S, Madsen JL, Holst JJ, Effect of 6-week course of glucagon-like peptide 1 on glycaemic control, insulin sensitivity, and beta-cell function in type 2 diabetes: a parallelgroup study, Lancet, 2002;359:824-30.

8. Drucker DJ, The biology of incretin hormones, Cell Metab, 2006;3:153-65.

9. Mentlein R, Dipeptidyl-peptidase IV (CD26) - role in the inactivation of regulatory peptides, Regul Pept, 1999;85:9-24.

10. Deacon CF, Alogliptin, a potent and selective dipeptidyl peptidase-IV inhibitor for the treatment of type 2 diabetes, Curr Opin Investig Drugs, 2008:9:402-13.

11. Thomas L, Eckhardt M, Langkopf E, et al., (R)-8-(3-aminopiperidin-1-yl)-7-but-2-ynyl-3-methyl-1-(4-methyl-quinazoli n2-ylmethyl)-3,7-dihydro-purine-2,6-dione (BI 1356), a novel xanthine-based dipeptidyl peptidase 4 inhibitor, has a superior potency and longer duration of action compared with other dipeptidyl peptidase-4 inhibitors, J Pharmacol Exp Ther, 2008; 325:175-82.

12. Rosenstock J, Sankoh S, List JF, Glucose-lowering activity of the dipeptidyl peptidase-4 inhibitor saxagliptin in drug-naive patients with type 2 diabetes, Diabetes Obes Metab, 2008; 10:376-86.

13. Gallwitz B, Sitagliptin: Profile of a novel DPP-4 inhibitor for the treatment of type 2 diabetes, Drugs Today (Barc), 2007;43: $13-25$.

14. Ristic S, Bates PC, Vildagliptin: a novel DPP-4 inhibitor with pancreatic islet enhancement activity for treatment of patients with type 2 diabetes, Drugs Today (Barc), 2006;42:519-31.

15. Madsbad S, Krarup T, Deacon CF, Holst JJ, Glucagon-like peptide receptor agonists and dipeptidyl peptidase- 4 inhibitors in the treatment of diabetes: a review of clinical trials, Curr Opin Clin Nutr Metab Care, 2008;11:491-9.

16. Williams-Herman $D$, Round $E$, Luo $E$, et al., The combination of sitagliptin and metformin is well tolerated in patients with type 2 diabetes: pooled analysis of 3028 patients in clinical trials for up to 2 years, Diabetes, 2008;57(Suppl. 1):A592.
17. Conarello SL, Li Z, Ronan J, et al., Mice lacking dipeptidyl peptidase IV are protected against obesity and insulin resistance, Proc Natl Acad Sci U S A, 2003;100:6825-30.

18. Williams-Herman D, Xu L, Davies MJ, et al., Substantial improvement in beta-cell function with initial combination therapy of sitagliptin and metformin in patients with type 2 diabetes after 1 yeat of treatment, Diabetes, 2008;57 (Suppl. 1):A161.

19. Dobs A, Goldstein BJ, Wieczorek L, et al., Triple combination therapy with sitagliptin, metformin, and rosiglitazone improves glycemic control in patients with type 2 diabetes, Diabetes, 2008;57(Suppl. 1):A-152.

20. Scherbaum WA, Schweizer A, Mari A, et al., Evidence that vildagliptin attenuates deterioration of glycaemic control during 2-year treatment of patients with type 2 diabetes and mild hyperglycaemia, Diabetes Obes Metab, 2008; Epub ahead of print.

21. Aschner P, Kipnes MS, Lunceford JK, Set al., Effect of the dipeptidyl peptidase-4 inhibitor sitagliptin as monotherapy on glycemic control in patients with type 2 diabetes, Diabetes Care, 2006;29:2632-7.

22. Nauck MA, Meininger $G$, Sheng $D$, et al., Efficacy and safety of the dipeptidyl peptidase-4 inhibitor, sitagliptin, compared with the sulfonylurea, glipizide, in patients with type 2 diabetes inadequately controlled on metformin alone: a randomized, double-blind, non-inferiority trial, Diabetes Obes Metab, 2007; 9:194-205.

23. Charbonnel B, Karasik A, Liu J, et al., Efficacy and safety of the dipeptidyl peptidase-4 inhibitor sitagliptin added to ongoing metformin therapy in patients with type 2 diabetes inadequately controlled with metformin alone, Diabetes Care, 2006;29:2638-43.

24. Raz I, Chen Y, Wu M, et al., Efficacy and safety of sitagliptin added to ongoing metformin therapy in patients with type 2 diabetes, Curr Med Res Opin, 2008;24:537-50.

25. Goldstein BJ, Feinglos MN, Lunceford JK, et al., Effect of Initia Combination Therapy with Sitagliptin, a Dipeptidyl Peptidase-4 Inhibitor, and Metformin on Glycemic Control in Patients with Type 2 Diabetes, Diabetes Care, 2007;30(8):1979-87.

26. Hermansen K, Kipnes M, Luo E, et al., Efficacy and safety of the dipeptidyl peptidase- 4 inhibitor, sitagliptin, in patients with type 2 diabetes mellitus inadequately controlled on glimepiride alone or on glimepiride and metformin, Diabetes Obes Metab, 2007;9(5):733-45.

27. Ahren $B$, What mediates the benefits associated with dipeptidyl peptidase-IV inhibition?, Diabetologia, 2005;48: 605-7.

28. Rosenstock J, Brazg R, Andryuk PJ, et al., Efficacy and safety of the dipeptidyl peptidase-4 inhibitor sitagliptin added to ongoing pioglitazone therapy in patients with type 2 diabetes: a 24-week, multicenter, randomized, double-blind, placebocontrolled, parallel-group study, Clin Ther, 2006;28:1556-8.
29. Raz I, Hanefeld M, Xu L, et al., Efficacy and safety of the dipeptidyl peptidase- 4 inhibitor sitagliptin as monotherapy in patients with type 2 diabetes mellitus, Diabetologia, 2006; 49:2564-71.

30. Scott R, Loeys T, Davies MJ, Engel SS, Efficacy and safety of sitagliptin when added to ongoing metformin therapy in patients with type 2 diabetes, Diabetes Obes Metab, 2008; Epub ahead of print.

31. Ahren B, Gomis R, Standl E, et al., Twelve- and 52-week efficacy of the dipeptidyl peptidase IV inhibitor LAF237 in metformin-treated patients with type 2 diabetes, Diabetes Care, 2004;27:2874-80.

32. Rosenstock J, Baron MA, Camisasca RP, et al., Efficacy and tolerability of initial combination therapy with vildagliptin and pioglitazone compared with component monotherapy in patients with type 2 diabetes, Diabetes Obes Metab, 2007;9: 175-85.

33. Garber AJ, Schweizer A, Baron MA, et al., Vildagliptin in combination with pioglitazone improves glycaemic control in patients with type 2 diabetes failing thiazolidinedione monotherapy: a randomized, placebo-controlled study, Diabetes Obes Metab, 2007;9:166-74.

34. Garber AJ, Foley JE, Banerji MA, et al., Effects of vildagliptin on glucose control in patients with type 2 diabetes inadequately controlled with a sulphonylurea, Diabetes Obes Metab, 2008; Epub ahead of print.

35. Pi-Sunyer FX, Schweizer A, Mills D, Dejager S, Efficacy and tolerability of vildagliptin monotherapy in drug-naive patients with type 2 diabetes, Diabetes Res Clin Pract, 2007;76:132-8.

36. Fonseca V, Schweizer A, Albrecht $D$, et al., Addition of vildagliptin to insulin improves glycaemic control in type 2 diabetes, Diabetologia, 2007:50:1148-55.

37. Bosi E, Camisasca RP, Collober C, et al., Effects of vildagliptin on glucose control over 24 weeks in patients with type 2 diabetes inadequately controlled with metformin, Diabetes Care, 2007;30:890-95.

38. Rosenstock J, Baron MA, Dejager S, et al., Comparison of vildagliptin and rosiglitazone monotherapy in patients with type 2 diabetes: a 24-week, double-blind, randomized trial, Diabetes Care, 2007;30:217-23.

39. Schweizer A, Couturier A, Foley JE, Dejager S, Comparison between vildagliptin and metformin to sustain reductions in $\mathrm{HbA}(1 \mathrm{c})$ over 1 year in drug-naive patients with type 2 diabetes, Diabet Med, 2007;24:955-61.

40. Bolli G, Dotta F, Rochotte E, Cohen SE, Efficacy and tolerability of vildagliptin vs. pioglitazone when added to metformin: a 24-week, randomized, double-blind study, Diabetes Obes Metab, 2008;10:82-90.

41. Dejager $\mathrm{S}$, Razac $\mathrm{S}$, Foley JE, Schweizer A, Vildagliptin in drugnaive patients with type 2 diabetes: a 24-week, double-blind, randomized, placebo-controlled, multiple-dose study, Horm Metab Res, 2007;39:218-23. 